\title{
Report of the Clinical Genetics Society Working Party on the role and training of clinical geneticists, September 1983*
}

The Working Party $\dagger$ was asked 'to consider the role and training of clinical geneticists so as to provide information and advice for trainees, other specialists, and administrators'.

Three main aims of clinical genetics were identified.

(1) By traditional clinical consultation to provide diagnosis, counselling, and other aspects of the management of genetic and part-genetic disorders in individual patients and families.

(2) To monitor and prevent such disorders at the population and epidemiological levels.

(3) To improve knowledge and ethical understanding by teaching, research, and debate.

The consultant clinical geneticist contributes to all of these aims and offers a unique combination of medical history taking, physical examination, diagnosis, pedigree analysis, risk calculation, and the communication skills of counselling. Other specifically medical qualifications and attributes are required and include the acceptance of personal clinical responsibility, an understanding of normal human physical variation, knowing when to seek other specialist opinion, and the use of invasive diagnostic procedures and occasionally of medications.

The general genetic clinic was identified as the main service provided by the consultant clinical geneticist and an associated team made up of medical staff, nurses, social workers, and others trained in home visiting, pedigree construction, and patient support, with appropriate secretarial and clerical services. Patients and relatives with genetic disorders of any organ system and of all ages are seen in these general clinics, on ward rounds, and on peripatetic visits to satellite clinics, schools, and institutions for the handicapped.

Broadly based general medical training in paediatrics and general medicine are essential with, in the UK, Membership of a Royal College. This is followed by higher specialist training in an approved senior registrar post, in which is acquired a sound

Received for publication 29 December 1983.

Accepted for publication 5 January 1984.

*The Working Party report, which contains details of a survey of patient referrals to general genetic clinics, manpower, and training facilities available in Britain, can be obtained from The Eugenics Society, 69 Eccleston Square, London SW1V 1PJ. Cost $£ 2 \cdot 25$.

$\dagger$ The composition of the working party was: Rodney Harris (Chairman), A E H Emery, A W Johnston, M E Pembrey, R Winter, and J Insley. knowledge of basic genetics (preferably to degree level) and wide clinical experience of all problems encountered in the general genetic clinic. $\neq$

The clinical geneticist has responsibility for education and research especially for undergraduate and postgraduate courses for doctors, nurses, and others who will be required for the planned improvement of genetic services.

Chromosome and other relevant laboratories should, ideally, be located under the same roof as the clinical geneticists who provide the main source of genetic counselling and clinical interpretation of complex investigations. The experience of clinical geneticists should be drawn upon for the development and timely introduction of new diagnostic tests and other improvements, while also helping to monitor the efficiency of existing services, including screening for fetal defects and for genetic disorders.

An optimum ratio of two consultant clinical geneticists per 2000000 population has been identified. This requires the creation of new consultant clinical geneticist posts and of training posts pro rata.

The number of referrals and degree of specialisation will in future require that physicians, paediatricians, obstetricians, and other consultants should be appointed with a special interest in clinical genetics. These will work alongside whole-time consultant clinical geneticists in the regional centres and in district general hospitals. The genetic component of their training should be supervised in the same way as that of clinical geneticists.

The terms of reference of the working party did not include laboratory geneticists, genetic nurses, social workers, and other essential members of the team but consideration must be given to their role, training, and career prospects.

The report emphasised the increasing complexity of medical genetics and the medicolegal problems likely to be encountered by doctors without genetic training who make incorrect clinical decisions on the results of specialised laboratory investigations.

RODNEY HARRIS

Department of Medical Genetics, St Mary's Hospital, Hathersage Road, Manchester M13 OJH.

$\ddagger$ Further details of training recommendations may be obtained from the Assistant Secretary, JCHMT, Royal College of Physicians,

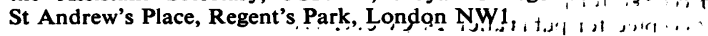

